\title{
The Effect Hofstede's Cultural Dimensions Have On Student-Teacher Relationships In The Korean Context
}

\author{
Alice Julianna Yoo, Hankuk University of Foreign Studies, South Korea
}

\begin{abstract}
This paper explores the role that culture plays in the classroom setting through Hofstede's Cultural Dimensions. Hofstede categorizes four dimensions of cultural differences, but this paper will focus on power distance, which Hofstede describes as the phenomenon in which less powerful members of a society accept inequality in power as a societal norm. The effect power distance has on student-teacher interactions in a Collectivist society, such as Korea, among South Korean University students and an EFL teacher from an Individualistic culture will be discussed.
\end{abstract}

Keywords: Hofstede's Cultural Dimensions; Power Distance; Collectivism; Individualism; Uncertainty Avoidance

\section{INTRODUCTION}

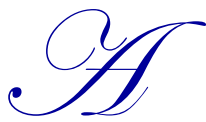

s social creatures, people have developed ways of communicating and interacting with different societies, establishing their own unique cultures. Furthermore, the concepts of language and culture are clearly and complexly interconnected "so that one cannot separate the two without losing the significance of either language or culture" (Brown, 2000, p. 177). Indeed, this complex relationship is reflected in certain cultural concepts, expressions, and idioms that exist in some languages but not in others. It is often a challenge for teachers to explain a completely foreign concept to students in a way that is understandable and most efficient. Precisely because of this complex interdependency between language and culture, teachers and students are faced with many challenges in the EFL classroom setting. This is especially evident when teachers and students come from highly different cultural backgrounds. Furthermore, with the rapid growth of globalization and an increasing interest, as well as importance in acquiring a second or even third language, the need to understand the role that culture plays in EFL classroom interactions and the effectiveness of such interactions on language learning outcomes is becoming more and more essential.

This paper discusses the various cultural challenges that hold relevance in the author's teacher-student and student-student interactions. More specifically, it focuses on one of Hofstede's cultural dimensions - small versus large power distance - and how it may have influenced classroom interactions with her students and how power distance, as well as her experiences with other cultural and social dynamics in the classroom settings, may have affected the teaching methodologies the author chose. The first part of this paper deals with discussions about Hofstede's Cultural Dimensions and details the author's own work context. Next, the author discusses how she approached and defined her relationship with her students and relates whether or not power distance may have had any influence in the teacher-student interactions, including comparisons of the author's own classroom interactions and the teacher-student interactions of her co-workers. The final sections of this paper explain the author's choice of methodology and further discusses whether or not the items on the list affected the methodology she adopted.

\section{Hofstede's Cultural Dimensions}

The concept of culture is one that holds broad definitions and implications, so as a result, it is rather difficult to quantify, especially for objective purposes. However, in one of his articles, Geert Hofstede attempts to clarify the confusion found in cross-cultural classroom settings by labeling, quantifying, and discussing various aspects of cultural differences found in most human societies. 
Hofstede breaks down the social interactions that people in almost every society are involved in and categorizes them. He labels the four major foundations in which social interactions take place as the institutions of family, school, job, and community, with their respective role pairs - parent/child and man/woman, teacher/student, boss/subordinate, and authority/member (Hofstede, 1986). Of course, such interactions are not necessarily found in all societies or hold equal value, but by creating categories such as those listed above, Hofstede helps make the comparison of various cultural interactions easier. He goes on to suggest that the role patterns "interact, so that ... patterns of parent/child interaction in a society are carried over into teacher/student ... relationships" (Hofstede, 1986). The implications of the affects that such role patterns can play in classroom interactions are further complicated by his added suggestion that "these archetypal roles are played in different ways" (Hofstede, 1986) in different societies. This, of course, can lead to clashes when the cultural perceptions of what appropriate classroom interactions are differ between students and teachers. Hofstede also attempts to identify and interpret the cultural differences that may be found in most societies under his 4-D Model of cultural differences.

In a large-scale study comparing over 50 countries, Geert Hofstede identifies what he calls the four dimensions of cultural differences that he suggests exist in these societies. He labels each dimension as individualism versus collectivism, large versus small power distance, strong versus weak uncertainty avoidance, and masculinity versus femininity (Hofstede, 1986). Although his ideas are insightful, the author will discuss whether or not power distance played a major role in the type of interactions that she had with her students.

\section{Power Distance}

Hofstede defines power distance as "the extent to which the less powerful persons in a society accept inequality in power and consider it as normal" (Hofstede, 1986). He further explains the dimension by dividing it into polar opposites as illustrated in Table 1.

Table 1: Small and Large Power Distance Societies

\begin{tabular}{|c|c|}
\hline Small Power Distance Societies & Large Power Distance Societies \\
\hline 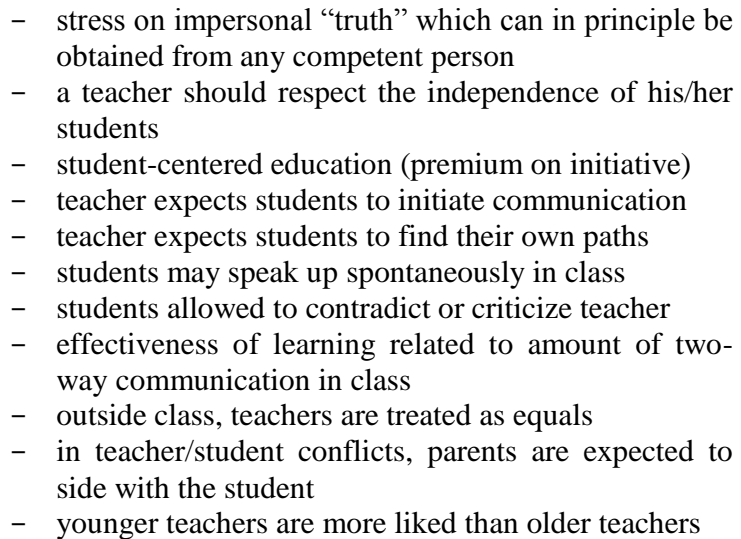 & $\begin{array}{l}\text { - } \text { stress on personal "wisdom" which is transferred in the } \\
\text { relationship with a particular teacher (guru) } \\
\text { - } \text { a teacher merits the respect of his/her students } \\
\text { - } \text { teacher-centered education (premium on order) } \\
\text { - } \text { students expect teacher to initiate communication } \\
\text { - } \text { students expect teacher to outline paths to follow } \\
\text { - } \text { students speak up in class only when invited by the teacher } \\
\text { - } \text { effectiveness of learning related to excellence of the } \\
\text { - } \text { teacher } \\
\text { - } \text { in teachect for teachers is also shown outside of class } \\
\text { - } \text { with the teacher conflicts, parents are expected to side } \\
\text { older teachers are more respected than younger teachers }\end{array}$ \\
\hline
\end{tabular}

Table 1 illustrates opposite extremes where on one end, members in small power distance societies view each other as relative equals. There is a small distinction in social inequalities by the less powerful members. At the other end, less powerful individuals in large power distance societies accept the inequalities in social power as normal; that is, individuals in large power distance societies place a great deal of importance on social status and positions of power. Venezuela and Panama are examples of countries that fall under the large power distance category, while countries such as Israel fall under the opposite extreme. However, although they may identify with or exhibit some qualities from either extreme, a great many societies, such as Korea and Canada, fall somewhere in the middle of the spectrum. Despite falling under different ranges in the dimensions labeled by Hofstede, the author will further focus on these two countries since she is a Canadian working as an EFL teacher in Korea. 


\section{Small/Large Power Distance and Author's Experiences in Canada and Korea}

Although an ethnic Korean, the author was born and raised in Canada, which she considers an example of an individualist culture as well as a small power distance society. There are some inequalities in teacher/student relationships in Canada where teachers are given positions of respect and power which is fully accepted by most students. However, as in most cases, the author's own classroom experiences were generally less formal and student-centered, as teachers encouraged the creativity of students and praised individualism. As a result of her own schooling experiences, the author had learned to adopt the same student-centered approach to education. The type of classroom interactions that she was familiar with, however, were almost non-existent or even frowned upon in Korea.

Historically, Korea has been a society dominated by traditional Confucius ideals. As a result, it is a highly collectivist culture with many characteristics of a large power distance society. It is even evident in the language, with informal, formal, and honorific forms of the language that must be observed in appropriate social settings. The author found the cultural differences between Canada and Korea quite apparent, especially in the amount of respect and power given to teachers by people of various social standings in Korean society. It is very much taboo to contradict someone of higher social status, especially a teacher. In fact, the author still finds it somewhat uncomfortable when some of her university students bow respectfully to her outside of class or when parents of younger students use an honorific form of the Korean word for teacher to address her. However, with globalization and a growing interest in English, Korea is slowly embracing Western cultures and individualist ideals, especially among the younger generation. It is this move toward globalization that has helped revolutionize the education system in Korea since the early 1990s; which will be discussed in the next section.

\section{English Education Reform in Korea}

The move toward globalization was accelerated by Korea's multilateral agreement with the World Trade Organization where foreign teachers and materials could freely enter the domestic market. As a result, Korea became a major market for English teaching materials by foreign publishers in the early 1990's (Kwon, 2000). However, perhaps the most striking reforms occurred with the inclusion of English as a required subject into the regular elementary school curriculum in 1997. Furthermore, the curriculum "required elementary English to be taught primarily through games, activities, songs, chants and role plays" (Kwon, 2000), which is indicative of a communicative approach to English education. With the growing importance of communicative competency in a country where the traditional Grammar Translation Method of teaching English had dominated its schools and failed to produce communicative proficiency in its students, there has been an increasing move toward the communicative approach to English in almost all its educational institutions, from private English kindergartens to public universities and even corporate companies. However, this shift in teaching methodologies has produced problems concerning teachers.

The ever-increasing wave of native English speakers entering the country to teach in EFL classrooms contributed to, and grew as a result of, the education revolution in Korea. This phenomenon occurred "based on the myth that native English teachers can teach English better than Korean English teachers ... and that any English speaker can teach English" (Park, 1999). However this belief can be problematic when looked at from a practical point of view, as the author had witnessed in her own work settings, with numerous clashes between foreign staff members and various Korean groups over the best teaching methodologies stemming mainly from cultural misunderstandings. In his article, Park (1999) identifies some of the problem issues listed below:

- $\quad$ information gap between foreign teachers and the Korean students

- $\quad$ power or comradeship issues between the foreign and Korean teachers

- interpersonal or intercultural problems between the foreign teachers and school administrators and the community

The attitudes of the foreign teachers and students were obviously major contributing factors to the concerns that were raised, which could also directly impact the success of the implementation of methodologies chosen for the EFL classes. 
Generally, it may be safe to assume that positive attitudes that learners have toward the teacher, target language, cultural group, and one's own language learning ability, can lead to "enhanced proficiency" (Brown, 2000, p. 181), while the opposite may be true with negative attitudes. Likewise, positive or negative cultural attitudes toward a specific group or society may help or hinder teachers in achieving positive interactions with their students in the classroom. It is therefore important for the teacher to be open-minded and understanding in a foreign culture and "sensitive to the fragility of students by using techniques that promote cultural understanding" (Brown, 2000, p. 189). Although the attitudes of both the teacher and learner are important, the burden of promoting cultural understanding should lie primarily on the shoulders of the teacher. Without a true understanding of the host country's cultural identity and its students' needs, the methodologies the teacher chooses and attempts to put into practice may be ineffective and interfere negatively with student-teacher interactions.

\section{Author's Student-Teacher Relationship}

Like many new teachers that come to teach English in Korea, the author had assumed that her own educational background could apply to the EFL setting. As a result, in order to make English fun and nonthreatening, she had first approached her class of kindergarten students as more of a friend and motherly caretaker than an authoritative figure. However, the author quickly learned that a certain amount of authority was necessary to keep the students disciplined, since the relationship was then taken advantage of. This may have resulted from the previously discussed role pattern of parent/child interactions being transferred over to teacher/student dynamics that Hofstede had described (Hofstede, 1986). It is important to understand that in a Confucian society like Korea's, teacher "is the most respected profession" (Hofstede, 1986) and the cultural role that teachers play as authority figures differs greatly from the role that friends or parents may play as caretakers, thus commanding a different level of respect. Moreover, children are generally given greater freedom from societal pressures, but once inside the classroom, they assume the role of a student and expect the teacher to lead and educate them. Again, this is indicative of the level of respect and social distance that exists in teacher-student relationships in a society like Korea's. This idea is further supported by the fact that parents frequently requested and relied on teachers to personally give instructions to the students since the children tended to obey the teacher more than the parents.

The author's teacher-student interactions with her university students, however, had slightly different dynamics in that they were already well-conditioned students by Korean standards. In other words, large power distance seemed to play a more pronounced role among these older students. The author found it much more difficult to get the students to actively communicate their ideas in class compared to her kindergarteners. The older students often had to be encouraged or prompted as they expected the professor to lead a more lecture-styled class. The vast majority of the author's university students were highly respectful of her and, as a result, there was a noticeable barrier to friendly informality in the relationship. Only a select few students, especially those who were already quite accomplished in English, wanted to develop an informal friendship with the teacher.

\section{Student-Teacher Relationship of Co-Workers versus that of Author}

Although power distance may have had some influences on the author's approach to teaching and the interactions she has with her students, the author feels that her own individual situation and personality may have played an equally important, or perhaps a greater role. Indeed, Hofstede was very insightful in his article and helped quantify the concept of culture and social interactions; however, he failed to take into consideration the importance of individual differences. Despite some of the cultural challenges the author faces in the classroom with her students, especially in the initial interactions, power distance seems to have a far greater influence on the teacher-student interactions of her foreign co-workers. In fact, the author has generally experienced very positive interactions with her students, whereas her co-workers have often experienced greater difficulties and problems. This discrepancy is probably due to the author's unique position as a fellow ethnic Korean whom the students can relate to more, as well as her own approach to the student-teacher relationship. Indeed, one of the most important elements in any social interaction is respect and, as the teacher and leader, the author was always careful to be sensitive to and respectful of the socio-cultural factors of the environment she was involved in. As a result, she was able to share a relationship based on mutual respect and understanding with the students and adopt methodologies that complimented the relationship. 


\section{METHODOLOGY}

Although many educational institutions in Korea have shown interest in moving to a more communicative approach to teaching with the education reform, the changes have been very gradual with many Koreans still reluctant to let go of the traditional Grammar Translation method. However, it is a step in the right direction, albeit a slow one.

The process of choosing an appropriate methodology for a class is a complicated and time-consuming one where a variety of factors must be taken into consideration. This process can be especially confusing and difficult in an EFL setting with students whose cultural identity and beliefs are different from the teacher's. Therefore, it is important for the teacher to develop an understanding of the students' needs, rather than adopt a method simply because it is a familiar one or one that the teacher was exposed to as a learner him or herself. After all, despite the universality of language teaching and learning, a method that is effective in one culture may be completely unsuccessful in another. This idea is further complicated by the fact that the educational experiences of the teacher were most likely as an L1 learner, whereas an EFL classroom involves students learning a second language. Obviously, the acquisition of language would differ under such contrasting situations. Unfortunately, the very mistake that many EFL teachers in Korea make is assuming that socio-cultural factors do not apply or hold little importance in the class, simply because the class is taught in English.

In the author's case, rather than systematically choose a particular methodology, she simply tried to meet the needs of her students, keeping within the curriculum and adjusting her classroom interactions whenever called for. The communicative approach and reflective teaching are perhaps the closest methods the author has adopted in the classroom. In the next section, these two approaches will be discussed as well as why the author chose to use them in her classes.

\section{Communicative Approach}

Due to the lack of communicative competence in English among language learners in Korea, the elements behind Communicative Language Teaching have become of great importance in many EFL classrooms. Although the theory is rather broad, some of the characteristics for the theoretical basis behind this approach are listed as follows (Richards \& Rogers, 2001, p. 161):

- $\quad$ Language is a system for the expression of meaning.

- The primary function of language is to allow interaction and communication.

- The structure of language reflects its functional and communicative uses.

- The primary units of language are not merely its grammatical and structural features, but categories of functional and communicative meaning as exemplified in discourse.

The goal, as stated by Richards and Rogers (2001, p. 167), is to promote the learner's communicative proficiency in the target language. The theory further outlines the roles that the teacher may assume as facilitator, independent participant, researcher and learner, needs analyst, counselor, and group process manager (Richards \& Rogers, 2001, p. 167). Again, the roles are rather general and varied, but it is the role as needs analyst that the author had found the most essential in helping to translate the chosen methodologies into successful teacher-student interactions. Of course, detailing the needs analysis of students is beyond the scope of this paper due to the complexity of the term itself (Miller, 2001); however, Brown (1995, p. 36) perhaps best describes this process through which the author satisfied "the language learning requirements of students within the context of particular institutions that influence the learning and teaching situation." The concepts of reflective teaching within the framework of the communicative approach to aid in classroom practices were also incorporated.

\section{Reflective Teaching}

Reflective teaching can be viewed as the teacher's critical self-evaluation of his or her teaching practices with the intention of professional growth (Richards \& Lockhart, 1996, p. ix). This approach "is often teacher initiated and directed" (Richards \& Lockhart, 1996, p. ix), whereas the communicative approach can be viewed as 
more student-centered. Such differences in both approaches may, on the surface, seem contradictory and at odds with each other, but through which the author found the formula for success. Her experiences as a teacher not only involved students of different ages, but of varying levels of language competence and all within the context of differing institutions, which resulted in circumstances that required an understanding of the students' needs and the ability to adjust her approach to teaching accordingly.

\section{Teaching as a Process}

Just as the approaches to language education continue to change and gain or lose in popularity in an everevolving society, no one particular teaching method may be satisfactory in a given classroom setting. Likewise, for many teachers, "a teaching approach is something uniquely personal, which they develop through experience and apply in different ways according to the demands of specific situations" or simply a "personal interpretation of what they think works best" (Richards \& Lockhart, 1996, p. 104). However, this approach, especially the latter in and of itself, may prove problematic, as was described previously, where the teacher may fail to take other factors, such as socio-cultural influences, into consideration. By also adopting the role of needs analyst, the author had found this approach important and beneficial in dealing with, and understanding, the elements involved in the learning processes of a second language and thereby developing a positive relationship with her students.

\section{Learning Process}

There is only so much a teacher can do when the power to accept the information that is taught is held by the students. This is why an awareness of the dynamics involved in the acquisition of a second language is crucial in any learning situation in helping to identify the specific needs of the students. For instance, the author had found that her younger students were, in general, less inhibited when it came to openly verbalizing in English and fairly quick, not only in acquiring new information, but also in using it. In contrast, most of her university students seemed to have far more difficulties with the language, especially in attempting to communicate, while those in the vast minority seemed to learn and speak with relative ease. The two common themes found to be associated with this discrepancy were motivation and confidence. As a result, through reflective teaching, the author also learned to adjust her classroom activities in order to facilitate positive interactions and outcomes for the various groups involved.

\section{Motivation and Confidence in Young Students}

Because young children are generally more impressionable, adaptable, and "less aware of language forms, and the possibility of making mistakes in those forms" (Brown, 2000, p. 65), most of the author's students were very communicative and actively participated in class. Furthermore, the classes were very small, with an average of only eight students. As a result, keeping the students motivated as a class mainly involved keeping the lessons fun and interactive, but also disciplined and culturally relatable. Of course, each student also had individual needs. By treating each individual as a respected and equally important, but special member of the class, the students responded by placing complete trust in the teacher. Students also responded positively to each other by helping each other and cooperating together. This helped weaker students build confidence and stronger students build a sense of responsibility. In fact, cooperation and improvement, not just high scores, were rewarded. The end result was a relationship, for teacher and students, based on mutual understanding and respect and a very positive learning outcome.

\section{University Students}

University students, however, presented a much greater challenge. Not only were the class sizes relatively large, with the average ranging from 35 to 40 students, their abilities ranged from beginner to advanced levels. Furthermore, the influences of cultural norms on the students were far more pronounced compared to the younger students. They also had various reasons for taking up a second language. All of these circumstances made it even more crucial for the author to be more aware of their needs, or at least their perceptions of what they felt they needed, and find ways to keep them motivated. The author basically approached her classes the same way she did with the younger students, but divided them into smaller groups. By keeping the groups small, more individual attention 
was provided and the students were far more interactive with each other, as well as with the teacher. Again, this generally resulted in great teamwork and positive learning outcomes.

\section{CONCLUSION}

Translating specific methods and approaches into successful classroom practices in EFL settings often presents many challenges and, just as societies shift and evolve with globalization, theories and teaching methods have also changed and will continue to change over time. Furthermore, the EFL classrooms themselves vary, depending on the students, teachers, curriculum, institution, and a host of other variables. As a result, the methodology adopted by the author reflected her attempts to meet the needs of her students in a changing world, rather than adopt a specific method or approach regardless of the situation. This was best accomplished through reflective teaching and the communicative approach. The author recognized that each of her students had different needs, motivations, and language abilities, and through Reflective Teaching, she was able to adjust her teaching practices to meet these specific situations.

Coming from a relatively small power distance society and working with students from a large power distance society, it was especially important for the author to be culturally sensitive and flexible in her teaching approach to the classes. Moreover, through reflective teaching, the author hopes to continue her own professional growth and evolution as an EFL teacher to help achieve the best learning outcome for the students.

\section{AUTHOR INFORMATION}

Alice Julianna Yoo has lived and worked in South Korea for almost 10 years. She has been a lecturer at the Hankuk University of Foreign Studies in South Korea for eight years and continues to teach the Practical English courses there to EFL freshmen students. She graduated from the University of British Columbia and completed her Master of Arts in TEFL/TESL at Birmingham University. E-mail: videlkorea@ yahoo.ca

\section{REFERENCES}

1. Brown, H. D. (2000). Principles of language learning and teaching. Addison Wesley Longman, Inc.

2. Brown, J. D. (1995). The elements of language curriculum; A systematic approach to program development. Heinle and Heinle Publishers.

3. Hofstede, G. (1986). Cultural differences in teaching and learning. International Journal of Intercultural Relations, 10, 301-320.

4. Kwon, O. (2000). Korea's English education policy changes in the 1990s: Innovations to gear the nation for the $21^{\text {st }}$ century. English Teaching, 55.

5. Miller, L. S. (2001). Needs analysis in a university English conversation program. English Teaching, 56.

6. $\quad$ Park, J. K. (1999). Teaching English: Korean culture and context. English Teaching, 54.

7. Richards, J. C., \& Lockhart, C. (1996) Reflective teaching in second language classrooms. Cambridge University Press.

8. Richards, J. C., \& Rodgers, T. S. (2001) Approaches and methods in language teaching. Cambridge University Press. 
NOTES 